\title{
Facial expression recognition in Alzheimer's disease: a longitudinal study
}

\author{
Reconhecimento da expressão facial na doença de Alzheimer: um estudo longitudinal \\ Bianca Torres', Raquel Luiza Santos ${ }^{1}$, Maria Fernanda Barroso de Sousa ${ }^{1}$, José Pedro Simões Neto², \\ Marcela Moreira Lima Nogueiraํ, Tatiana T. Belfort ${ }^{1}$, Rachel Dias ${ }^{1}$, Marcia Cristina Nascimento Dourado
}

\begin{abstract}
Facial recognition is one of the most important aspects of social cognition. In this study, we investigate the patterns of change and the factors involved in the ability to recognize emotion in mild Alzheimer's disease (AD). Through a longitudinal design, we assessed 30 people with AD. We used an experimental task that includes matching expressions with picture stimuli, labelling emotions and emotionally recognizing a stimulus situation. We observed a significant difference in the situational recognition task $(p \leq 0.05)$ between baseline and the second evaluation. The linear regression showed that cognition is a predictor of emotion recognition impairment $(p \leq 0.05)$. The ability to perceive emotions from facial expressions was impaired, particularly when the emotions presented were relatively subtle. Cognition is recruited to comprehend emotional situations in cases of mild dementia.
\end{abstract}

Keywords: facial expression recognition, Alzheimer's disease, emotional processing, face perception, emotion recognition.

\section{RESUMO}

O reconhecimento da expressão facial é um dos aspectos mais importantes relacionados à cognição social. Foram investigados os padrões de mudança e os fatores envolvidos na habilidade de reconhecer emoções na doença de Alzheimer (DA) leve. Em um estudo longitudinal foram avaliadas 30 pessoas com DA. Para a avaliação da capacidade de reconhecimento facial na DA foi utilizada uma tarefa experimental que inclui a combinação de expressões com uma figura estímulo, rotulação da emoção e reconhecimento emocional de uma situação estímulo. Foi encontrada diferença significativa entre os momentos 1 e 2 na tarefa de reconhecimento situacional ( $p \leq 0.05)$. A regressão linear mostrou que a cognição ( $p \leq 0.05$ ) é o fator preditor para o prejuízo do reconhecimento emocional, o que sugere um recrutamento da cognição para a compreensão de situações emocionais mais complexas. Houve comprometimento na percepção de emoções em expressões faciais, particularmente, quando as emoções eram sutis.

Palavras-chave: reconhecimento da expressão facial, doença de Alzheimer, processamento emocional, percepção facial, reconhecimento emocional.

Facial processing is an aspect of interpersonal communication and a modulator of social behavior ${ }^{1}$. In dementia, frontal-variant frontotemporal dementia (FTD) can impair social and emotional functioning ${ }^{2}$. Alzheimer's disease (AD) can also reduce aspects of emotion processing, which impairs social communication ${ }^{3}$ and autonomy ${ }^{4}$. However, researchers have not reached a consensus about whether people with $\mathrm{AD}$ cannot recognize facial affect. One study observed that people with $\mathrm{AD}$ could recognize and react to facial emotions even in severe stages of the disease ${ }^{5}$.

The few cross-sectional dementia studies that have investigated the ability to recognize facial emotion indicate that compared with age-matched controls, people with very mild dementia have difficulty labeling fearful, angry and happy expressions ${ }^{6}$. Additionally, people with mild to moderate $\mathrm{AD}$ have shown problems labeling sadness, surprise and disgust ${ }^{1}$. Moreover, Phillips et al. showed that in addition to the variance explained by executive functioning and depression scores, the ability to understand emotional expressions predicted quality of life. This finding is consistent with growing evidence that problems with identifying emotions may influence important indicators of interpersonal functioning, such as relationship well-being, social participation, and social competence ${ }^{7}$.

${ }^{1}$ Universidade Federal do Rio de Janeiro, Instituto de Psiquiatria, Centro de Doença de Alzheimer e Outros Transtornos Mentais da Velhice (CDA), Rio de Janeiro RJ, Brazil;

¿Universidade Federal de Santa Catarina, Departamento de Sociologia Política, Florianópolis SC, Brazil.

Correspondence: Bianca Torres; Rua Dr. Mario Vianna, 359/807 - Santa Rosa;24241-000 Niterói RJ, Brasil; E-mail: biatorres2@yahoo.com.br

Conflict of interest: There is no conflict of interest to declare.

Support: Foundation for Research from the Government of the State of Rio de Janeiro, Brazil - Fundação de Apoio à Pesquisa do Estado do Rio de Janeiro (FAPERJ) under Grant number E-26/102.256/2010".

Received 23 July 2014; Received in final form 09 December 2014; Accepted 29 December 2014. 
The general cognitive decline associated with $\mathrm{AD}$ has also been noted as the basis of the poorer performance of people with dementia on emotional processing tasks ${ }^{1,8,9,10}$. Shimokawa et al. suggested that there is a close relationship between intellectual ability and the capacity to recognize emotional situations because without sufficient intellectual ability, it is difficult to comprehend the nature of a given situation or the appropriate emotional state that one would experience in that situation ${ }^{11}$. However, McLellan et al. suggested that the general cognitive decline in $\mathrm{AD}$ does not seem to present a straightforward relation to the Mini-Mental State Examination (MMSE) or facial expression recognition tasks and that other factors may influence those abilities ${ }^{12}$.

Given that the accurate detection of the emotional states of others is essential to appropriate interactions, it is important to comprehend the patterns of change in the ability to recognize emotional expressions as dementia evolves. Further, it is interesting to investigate whether clinical characteristics of dementia can also influence the ability to identify and discriminate emotional expressions and situations over time. Therefore, we aim to investigate the patterns of change in the ability to recognize emotions in facial expressions among people with mild $\mathrm{AD}$ and to explore the sociodemographic and clinical factors that may influence facial emotion recognition in $\mathrm{AD}$ over time. Our hypothesis is that disease duration and overall cognitive impairment influence facial emotional recognition in $\mathrm{AD}$ over time.

\section{METHOD}

\section{Participants}

A convenience sample of 30 people with $\mathrm{AD}$ (22 females; 8 males) and their caregivers (26 females; 4 males) was selected from an $\mathrm{AD}$ outpatient unit between January 2012 and January 2013. The participants were diagnosed with possible or probable $\mathrm{AD}$ according to the Diagnostic and Statistical Manual of Mental Disorders, Fourth Edition (DSM-IV-TR) ${ }^{13}$ and the National Institute of Neurological and Communicative Diseases and Stroke/Alzheimer's Disease and Related Disorders Association (NINCDS-ADRDA) criteria $^{14}$. People with mild $\mathrm{AD}$ according to the Clinical Dementia Rating (CDR 1$)^{15}$ and scores ranging from 20 to 26 on the Mini-Mental State Examination (MMSE) ${ }^{16}$ were included in the study. To ensure that the findings were attributable to dementia rather than other clinical problems, people with $\mathrm{AD}$ with uncontrolled clinical problems, such as hypertension and diabetes, psychiatric disorders, aphasia, head trauma, alcohol abuse and epilepsy, as defined by the DSM-IV-TR criteria, were excluded from the study.

The clinical diagnosis of $\mathrm{AD}$ was made by a psychiatrist based on a clinical interview with the people with $\mathrm{AD}$ and their caregivers and on cognitive screening tests, laboratory tests and imaging studies. The diagnostic work-up include complete blood cell and platelet counts and the levels of glycemia, triglyceride, total cholesterol and fractions, alkaline phosphatase, glutamic oxaloacetic transaminase and glutamic pyruvic transaminase, bilirubin, urea, creatinine, total protein, calcium, free T4, TSH, VDRL, B12 and folate. All of the people with dementia were taking an anticholinesterase inhibitor (galantamine, $8.0 \mathrm{mg}, 16.0 \mathrm{mg}$, or $24.0 \mathrm{mg}$ [day]; donepezil, $10.0 \mathrm{mg}$ [day], or rivastigmine, $6.0 \mathrm{mg}, 9.0 \mathrm{mg}$, or $12.0 \mathrm{mg}$ [day]) before the study began. Likewise, the people with $\mathrm{AD}$ who had depressive symptoms were being treated with fluoxetine (20.0 mg), citalopram (20.0 mg), paroxetine (20.0 mg), or sertraline hydrochloride $(50.0 \mathrm{mg}$ ) prior to the study. Comorbidities, including hypothyroidism, hypercholesterolemia, hypertension, smoking, mitral valve prolapse, and diabetes were monitored.

The primary caregiver was defined as the main person responsible for care, and we included only informal caregivers (i.e., family members, friends, neighbors or volunteers). We excluded caregivers with a reported history of psychiatric or cognitive disorders. Our sample did not include any people with $\mathrm{AD}$ who had familial $\mathrm{AD}$. Each caregiver-person with dementia dyad met face-to-face at least once per week, and the caregivers were able to provide detailed information about their care recipients. All of the caregivers had been previously informed of the $\mathrm{AD}$ diagnosis by the psychiatrist. The people with $\mathrm{AD}$ completed assessments about facial recognition tasks, quality of life (QoL), cognition, and their awareness of their disease. The caregivers provided information about demographics and the person with AD's ability to perform activities of daily living (ADL), neuropsychiatric symptoms and dementia severity.

The subjects were evaluated longitudinally at two time points with an interval of six months, which will be referred to as M1 and M2 from this point forward. Both members of each dyad were interviewed together. The research assistant read the questions and presented large-type visual displays of the answer choices. When the people with $\mathrm{AD}$ expressed confusion about the question or the answer choices, the research assistant attempted to clarify the source of confusion. We presented the instruments in the same order for all of the participants. All of the assessments were conducted by trained research assistants.

\section{Measurements \\ Facial expression recognition ability}

To assess the ability to recognize facial expressions, we used FACES, an adaptation of an experimental task developed by Shimokawa et al. The original FACES has objects recognition tasks. However, as our study includes other visuospatial instruments, we decided to use only the tasks related to facial emotional recognition and recognition of emotional situations. The visual stimuli used in FACES are simple and did not have any features that could be seen as characteristic of any culture. FACES consists of four tasks that progressively increase in difficulty. Each task encompasses four problems 3 . 
Task 1 investigates the visuoperceptual ability to identify faces. It comprises a drawing of a face expressing a specific emotion (anger, happiness, surprise or sadness). This stimulus is followed by four other illustrations of faces showing specific emotions, including one that is exactly the same as the stimulus. Subjects are asked to select the illustration that is identical to the target.

Task 2 is slightly different; it aims to examine the ability to comprehend facial emotions. For this task, subjects are asked to select the drawing that best expresses the emotion shown at the top of the sheet. However, none of the drawings is exactly the same as the target stimulus, e.g., the stimulus is a drawing of a boy, while the four answer options are drawings of girls.

Task 3 examines whether subjects can recognize the expression of emotion conceptually. It investigates the subject's ability to comprehend a verbal label of emotion. A specific emotion (sadness, happiness, anger or surprise) is written on a label and shown to the person with $\mathrm{AD}$. The subjects are asked to indicate which of the four drawings best portrays this specific emotion. The examiner can provide clues, such as "Which face is the sad one?" if the person with $\mathrm{AD}$ hesitates to read the label.

Task 4 is the most complex one. It examines the person with AD's ability to comprehend the nature of a situation and the appropriate emotional state that one would experience in that situation. We showed the people with $\mathrm{AD}$ sketches of common scenes with obvious emotional content, such as a father receiving a gift from his children, two boys fighting, a boy being bitten by a crab and a boy crying because of an injury. The subjects were asked to indicate the drawing that best described the emotion he/she had inferred from the stimulus.

The subject's score is based on the number of correct answers. For each correct response, the subject receives one point. FACES is composed of 16 tasks, and the highest possible score is 16. Lower scores indicate impaired recognition.

\section{Severity of dementia}

We used the full protocol of the Brazilian validated version of the $\mathrm{CDR}^{15}$, in which the possible degrees of severity include 0 (no dementia), 0.5 (possible dementia), 1 (mild dementia), 2 (moderate dementia) and 3 (severe dementia).

\section{Quality of life}

We used the Brazilian validated version of the Quality of Life in Alzheimer's Disease scale (QoL-AD) $)^{17}$. This questionnaire was developed specifically to assess QoL in people with dementia. The QoL-AD includes 13 domains: physical health, energy, mood, living situation, memory, family, marriage, friends, chores, fun, money, self, and life as a whole. The 13 domains are rated as poor (1), fair (2), good (3) or excellent (4), and the total score ranges from 13 to 52.

\section{Cognition}

We used the Brazilian validated version of the $\mathrm{MMSE}^{16}$, an instrument that comprises tests of orientation, registration, short-term memory, language use, comprehension and basic motor skills. The total score ranges from 0 to 30 . Lower scores indicate impaired cognition.

\section{Functionality}

To measure the functional activities of people with $\mathrm{AD}$, we used the Pfeffer Functional Activities Questionnaire $(\mathrm{FAQ})^{18}$. The ratings for each item range from normal (0) to dependent (3), with a total of 30 points. Higher scores indicate worse functional status.

\section{Mood}

We used the Brazilian validated version of the Cornell Scale for Depression in Dementia (CSDD) ${ }^{19}$ to assess mood symptoms, physical signs, circadian functions and behavioral symptoms related to depression among people with dementia. Scores above 7 indicate the presence of depression.

\section{Neuropsychiatric symptoms}

The 12-item Brazilian validated version of the Neuropsychiatric Inventory (NPI-12) ${ }^{20}$ was used to assess the presence of delusions, hallucinations, dysphoria, anxiety, agitation/aggression, euphoria, disinhibition, irritability/lability, apathy, aberrant motor activity, nighttime behavior disturbances, and appetite and eating abnormalities.

\section{Awareness of the disease}

The Assessment Scale of Psychosocial Impact of the Diagnosis of Dementia (ASPIDD) is a 30-question scale based on the reports of people with dementia and their caregivers. This scale was designed to evaluate awareness of disease in people with dementia by scoring discrepant responses across domains that include awareness of cognitive deficits, emotional status, relationships, and ADLs. The caregiver answers the same questions as the person with dementia. The caregiver is not allowed to discuss the questions with the person with dementia or to assist him or her in any way. The discordance rate is calculated as the number of discrepant responses between the person with dementia and his or her caregiver. The awareness ratings are as follows: preserved (0 to 4), mildly impaired (5 to 11), moderately impaired (12 to 17) and absent (18 or more $)^{21}$.

\section{Ethical issues}

This study was approved by the Ethics Committee of the Institute of Psychiatry at the Federal University of Rio de Janeiro (UFRJ) CAAE0028.0.249.000-09. All of the people with $\mathrm{AD}$ were capable of providing signed, informed consent. The family caregivers also gave informed consent prior to the first interview. 


\section{Statistical analysis}

All statistical analyses were performed with SPSS software for Windows version 17.0. The Kolgomorov-Smirnov test was used to verify the normal distribution. The parametric variables were described by their mean and standard deviations (SD), and the non-parametric variables were described by their percentages. The sociodemographic and clinical characteristics (gender, age, schooling, marital status, duration and severity of illness, quality of life, cognition, functionality, mood, neuropsychiatric symptoms and awareness of the disease) of the people with $\mathrm{AD}$ were analyzed with descriptive statistics. We used Spearman's correlation to investigate the relationships of tasks 1, 2, 3, and 4 and the FACES total score at baseline (M1) with the second time point (M2). Spearman's correlations also explored the relationships of tasks 1, 2, 3, and 4 and the FACES total score with the sociodemographic data and clinical variables over time.

A linear regression was completed to identify the factors associated with the impairment in the FACES total score after six months. The independent variables included in the model were disease duration, CDR and MMSE.

All significance tests were performed at a two-tailed $\alpha$ level of 0.05 .

\section{RESULTS}

All people with $\mathrm{AD}$ completed both evaluations, and none dropped out of the study. The mean age was $77.23 \pm 7.21$ years, and they had a mean $8.83 \pm 4.04$ years of schooling. The mean duration of the illness was $4.7 \pm 2.6$ years, and the majority (56.7\%) of the people in our sample was widowers or single.

At M1, 100\% ( $\mathrm{n}=30)$ met the criteria for CDR1. At M2, only $56.7 \%(\mathrm{n}=17)$ of people with $\mathrm{AD}$ remained at CDR1; the other participants were all classified as moderate dementia (CDR2).

When evaluating the FACES scores (total and tasks 1, 2, 3 and 4) at M1 and M2, we found that there was only a significant difference for task $4(\mathrm{p} \leq 0.05)$. The clinical information for the people with $\mathrm{AD}$ at $\mathrm{M} 1$ and $\mathrm{M} 2$ is provided in Table 1.

\section{Baseline (M1)}

\section{Univariate analyses}

At M1, we only found a correlation between task 3 and the age of the people with $\mathrm{AD}(\mathrm{r}=-0.439 ; \mathrm{p} \leq 0.05)$. Task 4 was correlated with age $(r=-0.424 ; p \leq 0.05)$ and MMSE $(\mathrm{r}=0.367 ; \mathrm{p} \leq 0.05)$.

There were no correlations between tasks $1,2,3$, or 4 and $\mathrm{AD}$ depressive symptoms, neuropsychiatric symptoms, functionality, awareness of disease or QoL. Moreover, we did not find correlations between the FACES total score and sociodemographic or clinical variables. The Spearman's correlation obtained at M1 are presented in Table 2.

\section{After six months (M2)}

Functionality $(\mathrm{p} \leq 0.01)$ and cognition $(\mathrm{p} \leq 0.005)$ showed significant differences between moments 1 and 2 . There were no significant differences in the other clinical variables. We also found a significant difference between the two time points for the scores for task $4(t=2.386 ; p \leq 0.05)$, the most complex task.

\section{Univariate analysis}

Spearman's correlation showed that task 3 was correlated with the MMSE $(r=0.513 ; \mathrm{p} \leq 0.01)$. The FACES total score was correlated with disease duration $(r=-0.443 ; p \leq 0.05)$, MMSE $(r=0.620 ; p \leq 0.001)$ and CDR $(r=-0.370 ; p \leq 0.05)$.

There were no significant correlations between tasks 1 , 2 and 4 and sociodemographic or clinical variables at M2. Furthermore, there was no correlation between the FACES total score and other sociodemographic or clinical variables at M2. The results are shown in Table 3.

\section{Multivariate analysis}

The linear regression model examined the relationship between the FACES total score and the variables that were significantly correlated (cognitive state, clinical stage of dementia and disease duration). The linear regression indicated that the FACES total score was significantly related to cognitive state $(\mathrm{p} \leq 0.01)$. The final model of the predictors of the FACES total score explained $43.6 \%$ of the observed variance $(\mathrm{p} \leq 0.01)$. The adjusted $\mathrm{R}^{2}$ and standardized regression strength are shown in Table 4.

Table 1. FACES and clinical variables at baseline (M1) and after six months (M2).

\begin{tabular}{lccc}
\hline & \multicolumn{2}{c}{ Mean (SD) } & p-value \\
\cline { 1 - 2 } & M 1 $(n=30)$ & $M 2(n=30)$ & \\
MMSE & $21.5(3.0)$ & $19.7(3.5)$ & $0.005^{\star \star}$ \\
PFDD & $8.9(6.3)$ & $8.8(4.5)$ & 0.925 \\
NPI & $12.8(8.9)$ & $15.8(9.9)$ & $0.014^{\star}$ \\
QoL - AD & $12.0(11.9)$ & $14.8(12.3)$ & 0.173 \\
FACES Total & $31.2(4.8)$ & $30.43(5.7)$ & 0.427 \\
FACES 1 & $11.47(1.96)$ & $11.73(2.11)$ & 0.526 \\
FACES 2 & $3.57(0.57)$ & $3.53(0.68)$ & 0.831 \\
FACES 3 & $3.57(0.68)$ & $3.16(1.05)$ & 0.076 \\
FACES 4 & $2.83(0.83)$ & $3.00(0.95)$ & 0.305 \\
\hline SD:Standard & $1.50(1.04)$ & $2.03(1.22)$ & $0.024^{\star}$ \\
\hline
\end{tabular}

SD: Standard deviation; MMSE: Mini-Mental State Examination; CSDD: Cornell Scale for Depression in Dementia; PFAQ: Pfeffer Functional Activities Questionnaire; NPI: Neuropsychiatric Inventory; QoL-AD: Quality of Life in Alzheimer's disease. ${ }^{*} \mathrm{p} \leq 0.05 ;{ }^{* *} \mathrm{p} \leq 0.01$. 
Table 2. Spearman's correlations of FACES and the other variables at moment 1 (M1).

\begin{tabular}{lcccccccccc} 
& \multicolumn{2}{c}{ Task 1 } & \multicolumn{2}{c}{ Task 2 } & \multicolumn{2}{c}{ Task 3 } & \multicolumn{2}{c}{ Task 4 } & FACES total \\
\hline \multicolumn{1}{c}{} & $\mathrm{r}$ & $\mathrm{p}$ & $\mathrm{r}$ & $\mathrm{p}$ & $\mathrm{r}$ & $\mathrm{p}$ & $\mathrm{r}$ & $\mathrm{p}$ & $\mathrm{r}$ & $\mathrm{p}$ \\
\hline MMSE & 0.080 & 0.675 & -0.252 & 0.179 & 0.024 & 0.899 & 0.367 & $0.046^{\star}$ & 0.035 & 0.856 \\
CSDD & -0.005 & 0.978 & -0.303 & 0.103 & 0.041 & 0.829 & -0.260 & 0.165 & -0.181 & 0.340 \\
PFAQ & -0.228 & 0.225 & 0.132 & 0.487 & -0.196 & 0.299 & 0.014 & 0.943 & -0.011 & 0.952 \\
ASPIDD & -0.016 & 0.932 & 0.090 & 0.636 & -0.275 & 0.142 & -0.327 & 0.077 & -0.206 & 0.274 \\
NPI & -0.157 & 0.406 & -0.184 & 0.329 & -0.080 & 0.674 & -0.145 & 0.444 & -0.158 & 0.406 \\
QoL-AD & -0.031 & 0.873 & 0.079 & 0.677 & -0.361 & 0.050 & -0.067 & 0.725 & -0.202 & 0.283 \\
Age & -0.074 & 0.698 & 0.217 & 0.250 & -0.439 & $0.015 *$ & -0.424 & $0.019 *$ & -0.327 & 0.078 \\
Schooling & 0.267 & 0.154 & -0.085 & 0.655 & 0.105 & 0.580 & 0.252 & 0.179 & 0.191 & 0.313 \\
Duration of illness & 0.050 & 0.792 & 0.283 & 0.129 & -0.207 & 0.271 & -0.096 & 0.613 & -0.043 & 0.820 \\
\hline
\end{tabular}

SD: Standard deviation; MMSE: Mini-Mental State Examination; CSDD: Cornell Scale for Depression in Dementia; PFAQ: Pfeffer Functional Activities Questionnaire; NPI: Neuropsychiatric Inventory; QoL-AD: Quality of Life in Alzheimer's disease. ${ }^{*} p<0.05$.

Table 3. Spearman's correlation of FACES and the other variables at moment 2 (M2).

\begin{tabular}{lccccccccccc}
\hline & \multicolumn{2}{c}{ Task 1 } & \multicolumn{2}{c}{ Task 2 } & \multicolumn{2}{c}{ Task 3 } & \multicolumn{2}{c}{ Task 4 } & \multicolumn{2}{c}{ FACES total } \\
\hline MMSE & $\mathrm{r}$ & $\mathrm{p}$ & $\mathrm{r}$ & $\mathrm{p}$ & $\mathrm{r}$ & $\mathrm{p}$ & $\mathrm{r}$ & $\mathrm{p}$ & $\mathrm{r}$ & $\mathrm{p}$ \\
CSDD & 0.257 & 0.171 & 0.245 & 0.193 & 0.513 & $0.004^{\star \star}$ & 0.341 & 0.065 & 0.620 & $0.000^{\star \star \star}$ \\
PFAQ & -0.086 & 0.651 & 0.125 & 0.512 & 0.008 & 0.968 & 0.158 & 0.405 & 0.122 & 0.521 \\
ASPIDD & -0.082 & 0.666 & -0.167 & 0.379 & -0.202 & 0.284 & 0.017 & 0.930 & -0.194 & 0.305 \\
NPI & 0.250 & 0.182 & -0.104 & 0.585 & -0.125 & 0.511 & 0.149 & 0.431 & -0.002 & 0.992 \\
QoL-AD & -0.145 & 0.445 & 0.036 & 0.851 & -0.118 & 0.536 & -0.061 & 0.748 & -0.114 & 0.549 \\
Age & 0.276 & 0.140 & 0.095 & 0.617 & -0.037 & 0.848 & -0.025 & 0.896 & 0.047 & 0.804 \\
Schooling & 0.134 & 0.479 & 0.208 & 0.269 & -0.178 & 0.348 & -0.201 & 0.286 & 0.008 & 0.967 \\
Duration of illness & 0.030 & 0.876 & -0.123 & 0.518 & -0.035 & 0.856 & 0.446 & $0.014^{\star}$ & 0.188 & 0.319 \\
\hline
\end{tabular}

SD: Standard deviation; MMSE: Mini-Mental State Examination; CSDD: Cornell Scale for Depression in Dementia; PFAQ: Pfeffer Functional Activities Questionnaire; NPI: Neuropsychiatric Inventory; QoL-AD: Quality of Life in Alzheimer's disease. ${ }^{\star} p<0.05 ; * \star p<0.01 ; * \star \star p<0.001$.

Table 4. Regression model of factors predicting FACES total score.

\begin{tabular}{lcccc}
\hline B & $\beta$ & $R^{2}$ & Adj. $R^{2}$ & Significance \\
\hline MMSE 0.382 $\left(p=0.000^{\star \star *}\right)$ & 0.382 & 0.436 & 0.436 & $0.000 * \star \star$ \\
\hline MMSE: Mini Mental State Examination. ${ }^{* \star *} p<0.001$.
\end{tabular}

\section{DISCUSSION}

We longitudinally investigated the patterns of change in the ability to recognize facial emotional expressions among people with mild $\mathrm{AD}$ using FACES, an experimental task adapted from Shimokawa et al. ${ }^{11}$. Our results show that people with $\mathrm{AD}$ performed significantly worse on task 4 over time, which differed from the results for the first 3 FACES tasks. Task 4, the most subtle and abstract task, examined the ability to comprehend the nature of a situation and the appropriate emotional state that one would experience in that situation.

Our first major finding is that people with mild $\mathrm{AD}$ maintain the ability to recognize and discriminate simple facial emotions. The second major finding is that in mild dementia, more complex emotional situations are the first aspect to become impaired in $\mathrm{AD}$. In this manner, it is possible to assume that people with $\mathrm{AD}$ may experience a progressive impairment in the ability to process affective information, including a specific impaired ability to recognize facial expressions of emotion ${ }^{12}$.
Our results are in line with those of Shimokawa et al. ${ }^{11}$, who applied the original experimental task we used. They found that people with $\mathrm{AD}$ performed better than people with vascular dementia on all tasks except in the fourth, even though there was no difference between these two groups of patients in terms of their general cognition and visuoperceptual abilities ${ }^{11}$. Another study suggested that when more subtle emotions were shown, people with $\mathrm{AD}$ reported deficits in identifying all emotions ${ }^{7}$. Given that the emotions experienced in everyday life are often slight and complex, our finding that in $\mathrm{AD}$ there are problems in detecting subtle emotions indicates that these difficulties may have important social consequences. Interpersonal and social problems are often a feature of $\mathrm{AD}$. These problems may be associated with increased caregiver burden and are potentially a major factor in decreased quality of life ${ }^{12}$. Further studies should investigate the relationship between facial emotion recognition and caregiver burden.

Shimokawa et al., in their cross-sectional study, also found a significant correlation between the MMSE score and the total emotion recognition task score in people with vascular dementia, whereas no correlation was found between cognitive impairment and $\mathrm{AD}^{3}$. The authors suggested that the general cognitive performance measured by the MMSE is independent of the performance on emotion recognition 
tasks in $\mathrm{AD}$. In contrast, we found that in mild $\mathrm{AD}$, facial emotion recognition is influenced by disease progression and overall cognitive impairment, as measured by the MMSE. The present longitudinal data support the assumption that even in mild $\mathrm{AD}$, several cognitive functions were engaged when a complex emotional task is undertaken. Deficits in the perception of affection tasks may be related to cognitive deficits presented by people with $\mathrm{AD}$ and not the result of a primary impairment in emotion perception. Although emotional processing can be considered a non-cognitive ability per se, the cognitive impairments that emerge even in the early stages of dementia can hamper this ability ${ }^{7}$. Thus, disease progression (disease duration or MMSE) should be taken into account during the diagnostic evaluation of facial emotion recognition in $\mathrm{AD}$. In addition, further studies should assess cognition using a more complete test battery to better investigate the relationship between emotion recognition and cognitive state in dementia.

Facial emotion recognition has been related to quality of life $^{7}$, behavior and $\operatorname{mood}^{22}$; however, we did not find a significant relationship between the FACES scores and other clinical variables, such as mood, neuropsychiatry symptoms or functionality. We can argue that our mildly impaired sample presented a little variability in these aspects, and the time interval between both evaluations was short. Further longitudinal studies should be designed to assess the relationship between facial emotion recognition and clinical variables at different time points alongside the disease progression.

The present study has some limitations. First, cognitive impairment was evaluated using the MMSE alone. A neuropsychological battery would provide a more thorough exploration of the cognitive and perceptual components of emotion perception. Also, we did not include a control group, and our study enrolled a small sample. In addition, we did not conduct power analysis to verify the appropriateness of the sample size. Finally, the short time interval between assessments may have hampered the observation of the relationship between the facial expression recognition and other variables.

Our findings suggest that people with mild $\mathrm{AD}$ have difficulties making emotional interpretations of the environment, mostly because of their worsening global cognition. People with $\mathrm{AD}$ had an impaired ability to perceive emotions from situations, particularly when the emotions presented were relatively subtle. Additionally, cognition is recruited for the comprehension of emotional situations in cases of mild dementia. It seems that $\mathrm{AD}$ patients have to use cognitive global functions to complete emotion comprehension tasks.

Misreading the emotions of others may be an aspect of the inability that people with $\mathrm{AD}$ presents to employ external and internal emotional cues to modify their behavior and adjust their self-perceptions. Impairments in facial processing may lead to poor judgment in social interactions and to behavior disturbances ${ }^{1}$. Given the potential importance of emotion perception for wider social functioning, intervention and treatment, studies in dementia should consider measuring emotional perception as an outcome measure along with the more usual battery of cognitive tests. Clinically, our results may be useful to help caregivers, family members and professionals choose more appropriate and intelligible communication styles when treating people with dementia.

\section{References}

1. Hargrave R, Maddock RJ, Stone V. Impaired recognition of facial expressions of emotion in Alzheimer's disease. J Neuropsychiatry Clin Neurosci. 2002;14(1):64-71. http://dx.doi.org/10.1176/appi.neuropsych.14.1.64

2. Lavenu I, Pasquier F, Lebert F, Petit H, Van der Linden M. Perception of emotion in frontotemporal dementia and Alzheimer's disease. Alzheimer Dis Assoc Disord. 1999;13(2):96-101. http://dx.doi.org/10.1097/00002093-199904000-00007

3. Shimokawa A, Yatomi N, Anamizu S, Ashikari I, Kohno M, Maki Y et al. Comprehension of emotions: comparison between Alzheimer type and vascular type dementias. Dement Geriatr Cogn Disord. 2000;11(5):268-74. http://dx.doi.org/10.1159/000017249

4. Bediou B, Ryff I, Mercier B, Milliery M, Hénaff MA, D’Amato Tet al. Impaired social cognition in mild Alzheimer disease.J Geriatr Psychiatry Neurol. 2009;22(2):130-40. http://dx.doi.org/10.1177/0891988709332939

5. Guaita A, Malnati M, Vaccaro R, Pezatti R, Marcionetti J, Vitali SF et al. Impaired facial emotion recognition and preserved reactivity to facial expressions in people with severe dementia. Arch Gerontol Geriatr. 2009;49 Suppl:135-46. http://dx.doi.org/10.1016/j.archger.2009.09.023

6. Henry JD, Ruffman T, McDonald S, O'Leary MA, Phillips LH, Brodaty $\mathrm{H}$ et al. Recognition of disgust is selectively preserved in Alzheimer's disease. Neuropsychologia. 2008;46(5):1363-70. http://dx.doi.org/10.1016/j.neuropsychologia.2007.12.012
7. Phillips LH, Scott C, Henry JD, Mowat D, Bell JS. Emotion perception in Alzheimer's disease and mood disorder in old age. Psychol Aging. 2010;25(1):38-47. http://dx.doi.org/10.1037/a0017369

8. Albert MS, Cohen C, Koff E. Perception of affect in patients with dementia of the Alzheimer type. Arch Neurol. 1991;48(8):791-5. http://dx.doi.org/10.1001/archneur.1991.00530200027013

9. Roudier M, Marcie P, Grancher AS, Tzortzis C, Starkstein S, Boller F. Discrimination of facial identity and of emotions in Alzheimer's disease. J Neurol Sci. 1998;154(2):151-8. http://dx.doi.org/10.1016/S0022-510X(97)00222-0

10. Satler C, Uribe C, Conde C, Da-Silva SL, Tomaz C. Emotion processing for arousal and neutral content in Alzheimer's disease. Int J Alzheimers Dis. 2009;ID 278615:1-6. http://dx.doi.org/10.4061/2009/278615

11. Shimokawa A, Yatomi N, Anamizu S, Torii S, Isono H, Sugai Y. Recognition of facial expressions and emotional situations in patients with dementia of the Alzheimer and vascular types. Dement Geriatr Cogn Disord. 2003;15(3):163-8. http://dx.doi.org/10.1159/000068479

12. McLellan T, Johnston L, Dalrymple-Alford J, Porter R. The recognition os facial expressions of emotion in Alzheimer's disease: a review of findings. Acta Neuropsychiatr. 2008;20(5):236-50. http://dx.doi.org/10.1111/j.1601-5215.2008.00315.x

13. American Psychiatric Association, Diagnostic and statistical manual of mental disorders, 4th ed. Washington, DC: American Psychiatric Association; 2000. 
14. McKhann G, Drachman D, Folstein M, Katzman R, Price D, Stadlan EM. Clinical diagnosis of Alzheimer's disease: report of the NINCDSADRDA Work Group under the auspices of Department of Health and Human Services Task Force on Alzheimer's Disease. Neurology. 1984;34(7):939-44. http://dx.doi.org/10.1212/WNL.34.7.939

15. Maia ALG, Godinho C, Ferreira ED, Almeida V, Schuh A, Kaye J et al. Application of the Brazilian version of the CDR scale in samples of dementia patients. Arq Neuropsiquiatr. 2006;64(2B):485-9 http://dx.doi.org/10.1590/S0004-282X2006000300025

16. Bertolucci PH, Brucki SM, Campacci SR, Juliano Y. The mini-mental state examination in a outpatient population: influence of literacy. Arq Neuropsiquiatr. 1994;52(1):-7. http://dx.doi.org/10.1590/S0004-282X1994000100001

17. Novelli MM, Nitrini R, Caramelli P. Validation of the Brazilian version of the quality of life scale for patients with Alzheimer's disease and their caregivers (QoL-AD). Aging Ment Health. 2010;14(5):624-31. http://dx.doi.org/10.1080/13607861003588840

18. Pfeffer RI, Kurosaki TT, Harrah CH Jr, Chance JM, Filos S. Measurement of functional activities in older adults in the community. J Gerontol. 1982;37(3):323-9. http://dx.doi.org/10.1093/geronj/37.3.323

19. Carthery-Goulart MT, Areza-Fegyveres R, Schultz RR, Okamoto I, Caramelli P, Bertolucci PHF et al. Versão brasileira da Escala Cornell de depressão em demência (Cornell depression scale in dementia). Arq Neuropsiquiatr, 2007;65(3B):912-5. http://dx.doi.org/10.1590/S0004-282X2007000500037

20. Camozzato, AL, Kochhann R, Simeoni C, Konrath CA, Franz AP, Carvalho A et al. Reliability of the Brazilian Portuguese version of the Neuropsychiatric Inventory (NPI) for patients with Alzheimer's disease and their caregivers. Int Psychogeriatr. 2008;20(2):383-93. http://dx.doi.org/10.1017/S1041610207006254

21. Dourado MCN, Mograbi D, Santos RL, Sousa MF, Nogueira ML, Belfort Tet al. Awareness of disease in dementia: factor Structure of the assessment scale of psychosocial impact of the diagnosis of dementia. Int J Alzheimers Dis. 2014;41(3):947-56. http://dx.doi.org/10.3233/JAD-140183.

22. Shimokawa A, Yatomi N, Anamizu S, Torii S, Isono H, Sugai Y et al. Influence of deteriorating ability of emotional comprehension on interpersonal behavior in Alzheimer-type dementia. Brain Cogn. 2001;47(3):423-33. http://dx.doi.org/10.1006/brcg.2001.1318 